\section{PET-CT meltdown is looming}

I was hoping to publish an editorial by a renowned overseas expert in the field of PET-CT; this has not been possible but I hope it will appear in the next issue of the SAJR.

Developments around PET-CT are of critical importance to state-ofthe-art medicine in this country. I experience a feeling of déjà $v u$ when I hear that South Africa cannot afford technology of this nature. Ten years ago, I had to counter such arguments against magnetic resonance - and today there is universal agreement that MRI is probably the most efficient and cost-saving modality in medicine. Gone are the days of extended hospitalisation for diagnostic 'tests'. Non-acute patients are diagnosed on an outpatient basis, and it may be an interesting calculation to identify the effect that this has had on the budgets of medical aids and state hospitals.
We are now hearing that PET-CT is finding it difficult to survive. There are even prognostications that PET centres may have to close down and that the modality may disappear from the diagnostic scene in this country - regressing us to past times when a $1 \mathrm{~cm}$ node spells malignant and a $9 \mathrm{~mm}$ node is debatable. I intend to continue this issue in the next edition of the $S A J R$, when we can weigh the consequences against the perspective of an objective editorial of international authority in the field of cancer therapy. But at this point, it's enough to state that if this modality disappears from the South African scene, it will probably not return for a decade or more. I believe that this would be disastrous for everyone in the field of cancer diagnosis and therapy.

Thanks to Savvas Andronikou for conceptualising and compiling RADIOACTIVE NEWS. This is a news forum for South African Radiology, and I welcome contributions from the Society, College and all our university departments.

\section{Jan Lotz}

Editor-in-chief 